\title{
Renal Glomeruli and Tubular Injury Following Indomethacin, Ibuprofen, and Gentamicin Exposure in a Neonatal Rat Model
}

\author{
ALISON L. KENT, LESLEY E. MAXWELL, MARK E. KOINA, MICHAEL C. FALK, DAVID WILLENBORG, \\ AND JANE E. DAHLSTROM
}

\begin{abstract}
Department of Neonatology [A.L.K.], Department of Anatomical Pathology [L.E.M., M.E.K., J.E.D.], The Canberra Hospital, Woden, Australian Capital Territory 2606, Australia; Department of Nephrology [M.C.F.], Neurosciences Research Unit [D.W.], Australian National University, Canberra, Australian Capital Territory 2600, Australia; Australian National University Medical School [A.L.K., D.W., J.E.D.], Canberra, Australian Capital Territory 2600, Australia
\end{abstract}

\begin{abstract}
Indomethacin, ibuprofen, and gentamicin are commonly administered to neonates between 24 and 28 wk gestation when glomerulogenesis is still occurring. Indomethacin is known to cause renal failure in up to $25 \%$ of infants treated. Possible morphologic effects of these drugs are largely unknown. The purpose of this study was to determine the type of renal changes found on light (LM) and electron microscopy (EM) following administration of indomethacin, ibuprofen, and gentamicin in a neonatal rat model. Rat pups were exposed to indomethacin or ibuprofen and/or gentamicin antenatally for $5 \mathrm{~d}$ before birth or postnatally for $5 \mathrm{~d}$ from $\mathrm{d} 1$ of life. Pups were killed at $14 \mathrm{~d}$ of age. LM examination in all indomethacin- and ibuprofen-treated pups both antenatally and postnatally showed vacuolization of the epithelial proximal tubules, interstitial edema, intratubular protein deposition but no significant glomerular changes. EM examination showed pleomorphic mitochondria and loss of microvilli in the tubules. The glomeruli showed extensive foot process effacement and irregularities of the glomerular basement membrane. EM changes were most marked in pups treated antenatally with ibuprofen, and indomethacin with gentamicin postnatally. Indomethacin, ibuprofen, and gentamicin cause significant change in glomerular and tubular structure in the neonatal rat model. (Pediatr Res 62: 307-312, 2007)
\end{abstract}

$\mathrm{U}^{\mathrm{p}}$ p to $5 \%$ of infants are delivered between 24 and $28 \mathrm{wk}$ gestation, at a time when glomerulogenesis is occurring. Indomethacin and ibuprofen are commonly used in extremely premature neonates to close a patent ductus arteriosus at this time $(1,2)$. Both of these drugs are successful in closing the ductus $(3,4)$, but the morphologic effects these drugs may have on the developing kidney are unknown. Both drugs are known to be nephrotoxic, with indomethacin causing acute renal failure in $25 \%$ of premature neonates treated (5). Ibuprofen is considered to have less renal toxicity than indomethacin, but is as efficacious as indomethacin at closing the patent ductus (6). Two animal studies have shown an effect on glomerulogenesis by ibuprofen and a COX-2 selective inhibitor. In both studies, the number and size of glomeruli was decreased $(7,8)$.

Gentamicin is frequently administered at the same time as indomethacin or ibuprofen. Gentamicin has been shown in in

Received November 27, 2006; accepted April 9, 2007.

Correspondence: Alison Kent, M.D., Department of Neonatology, The Canberra Hospital, PO Box 11, Woden, Australian Capital Territory 2606, Australia; e-mail: alison.kent@act.gov.au

This project was funded by The Canberra Hospital Private Practice Fund. vitro studies to affect nephron development (9). The combination of nonsteroidal anti-inflammatory drugs (NSAID) and gentamicin on glomerular development is unknown. The renal effect of indomethacin has not been examined in a neonatal animal model, nor has the combination of both indomethacin or ibuprofen and gentamicin.

In the human, glomerulogenesis is complete at $36 \mathrm{wk}$ gestation. The metanephron develops at $5 \mathrm{wk}$ gestation, with vesicular glomeruli development occurring at 18 wk gestation. Glomerular tubular development occurs from 24 wk gestation and is complete at $36 \mathrm{wk}(10-12)$. In the rat model, glomerulogenesis continues after birth until $14 \mathrm{~d}$ of life (13). At birth the neonatal rat kidney is similar to that of a 24-wk gestation human fetus.

Reduction in the number of glomeruli has been implicated in the development of hypertension and subsequent cardiovascular disease in animal models and human studies (14-18). The use of nephrotoxic drugs during this period of glomerulogenesis may cause glomerular injury and result in a decreased number of glomeruli that may result in renal disease later in life.

The aim of this study was to determine in a neonatal rat model whether there is light or electron microscopic evidence of tubular and glomerular injury following exposure to antenatal indomethacin or ibuprofen; postnatal indomethacin or ibuprofen; or postnatal indomethacin or ibuprofen in combination with gentamicin.

\section{METHODS}

Sprague-Dawley pregnant dams were obtained from the Animal Resource Centre (Perth, WA, Australia). The animal experiments were approved by the Australian National University Animal Ethics Committee and treatment and care of the animals conformed to the Australian Code of Practice for the Care and Use of Animals for Scientific Purposes.

Control animals consisted of pregnant dams and their offspring having no drug treatment during pregnancy or their pups receiving intraperitoneal saline.

Eleven groups of experimental animals were established. The method of administration, timing and dose of medication are detailed in Table 1. The timing and doses of medication are similar to those used clinically in the human neonate.

Immediately after sacrificing the pups, the abdominal and chest organs were exposed using a midline incision. A butterfly needle was inserted and clamped into the left ventricle and an incision made into the right atrium. To prevent clotting, heparin sodium 1 U/g body weight (Astra Zeneca Pty Ltd., Sydney, Australia) was instilled into the circulation. To dilate the vasculature, papaverine hydrochloride $1.2 \mathrm{mg}$ dose (David Bull Laboratories, Melbourne, Australia) was administered. The vasculature was then cleared with $0.9 \%$ sodium chloride and then perfusion-fixed with $2.5 \%$ glutaraldehyde (ProSciTech Pty. Ltd., Townsville, Australia) in $0.1 \mathrm{M}$ phosphate buffer. The right and left kidneys were then excised. The right kidney was placed in $2.5 \%$ glutaraldehyde while the left kidney was placed in $10 \%$ buffered formalin. 
Table 1. Control and experimental groups route, timing, and dose of medication

\begin{tabular}{clll}
\hline Group & \multicolumn{1}{c}{ Route } & \multicolumn{1}{c}{ Timing } & \multicolumn{1}{c}{ Drug and dose } \\
\hline 1 & Nil & Nil & Nil \\
2 & Intraperitoneal & Postnatal d 1-5 & Normal saline \\
3 & Oral & Antenatal d 16-20 & Indomethacin $0.5 \mathrm{mg} / \mathrm{kg}$ \\
4 & Oral & Antenatal d 16-20 & Indomethacin $1.0 \mathrm{mg} / \mathrm{kg}$ \\
5 & Oral & Antenatal d 16-20 & Ibuprofen $10 \mathrm{mg} / \mathrm{kg}$ \\
6 & Oral & Antenatal d 16-20 & Ibuprofen $20 \mathrm{mg} / \mathrm{kg}$ \\
7 & Intraperitoneal & Postnatal d 1-5 & Indomethacin $0.1 \mathrm{mg} / \mathrm{kg}$ \\
8 & Intraperitoneal & Postnatal d 1-5 & Indomethacin $0.2 \mathrm{mg} / \mathrm{kg}$ \\
9 & Intraperitoneal & Postnatal d 1-5 & Ibuprofen $5 \mathrm{mg} / \mathrm{kg}$ \\
10 & Intraperitoneal & Postnatal d 1-5 & Ibuprofen $10 \mathrm{mg} / \mathrm{kg}$ \\
11 & Intraperitoneal & Postnatal d 1-5 & Gentamicin $2.5 \mathrm{mg} / \mathrm{kg}$ \\
12 & Intraperitoneal & Postnatal d 1-5 & Indomethacin $0.1 \mathrm{mg} / \mathrm{kg}+$ \\
& & & gentamicin $2.5 \mathrm{mg} / \mathrm{kg}$ \\
13 & Intraperitoneal & Postnatal d 1-5 & Ibuprofen $5 \mathrm{mg} / \mathrm{kg}+$ \\
& & & gentamicin $2.5 \mathrm{mg} / \mathrm{kg}$ \\
\hline
\end{tabular}

Light microscopy. Following fixation in $2.5 \%$ glutaraldehyde for $5 \mathrm{~h}$ the kidney tissue was transferred into $10 \%$ buffered formalin for $24 \mathrm{~h}$ before processing and embedding into paraffin. Two $4-\mu \mathrm{m}$ sections were cut from each sample and stained with hematoxylin and eosin. Special histochemical stains [periodic acid Schiff with methenamine silver (PASM) and Trichrome stains] were also performed to better assess the basement membranes and capillary loops.

Electron microscopy. Kidneys were fixed in $2.5 \%$ glutaraldehyde (ProSciTech Pty. Ltd.) for $5 \mathrm{~h}$ and then postfixed with $0.1 \mathrm{M}$ cacodylate-buffered $2 \%$ osmium tetroxide (ProSciTech Pty. Ltd.) for 2 h. En bloc staining with 2\% aqueous uranyl acetate (ProSciTech Pty. Ltd.) preceded dehydration through a graded series of ethanol steps. Specimens were infiltrated with Spurrs resin and set overnight at $70^{\circ} \mathrm{C}$. Three levels of thin sections $(100 \mathrm{~nm})$ were cut from three blocks of each rat pup with a minimum of two rat pups from each group examined. Thin sections mounted on copper/palladium grids were stained with Reynold's lead citrate and viewed on a Jeol 1011 transmission electron microscope. Images were captured using a MegaView III digital camera and AnalySis software.

\section{RESULTS}

In all groups, 4-15 pups survived to $\mathrm{d} 14$.

Control groups. LM examination of both control groups (no treatment and intraperitoneal saline) revealed no tubular or glomerular changes. LM findings in the saline treated group had no significant changes.
The control group receiving no treatment showed normal tubular and glomerular architecture. The saline control group did not fix appropriately and were unable to undergo EM examination.

Intrauterine exposure to indomethacin or ibuprofen. The proximal tubules of the kidneys from these animals show granular cytoplasm with small intracytoplasmic vacuolative change. Small vacuoles were seen on the surface of these cells. Rare lymphocytes were seen in the interstitium of the renal cortex and medulla. Interstitial edema was most obvious in the indomethacin treated animals in the region of the corticomedullary junction. The glomeruli were unremarkable (Table 2).

Extensive foot process effacement (70-80\%), basement membrane changes with laminations, protrusions and lucency were seen in all groups (Fig. 1, A-C). All of the sections in each group showed predominately distal tubular changes consisting of pleomorphic mitochondria, loss of microvilli, and some inflammatory cells. Vacuoles containing a small amount of lucent protein material were seen mainly in the proximal tubules. The most significant changes were seen in the group receiving $20 \mathrm{mg} / \mathrm{kg} / \mathrm{d}$ of ibuprofen (Table 2).

Postnatal exposure to indomethacin or ibuprofen or in combination with gentamicin-Light microscopy. The proximal tubules in all groups, especially in the region of the corticomedullary junction, showed prominent vacuolization and granularity of the cytoplasm of the tubular epithelial cells as well as some large intraluminal vacuole formation. This was most prominent in the groups of rats treated with both indomethacin or ibuprofen and gentamicin (Fig. 2A). Rare lymphocytes were seen in the interstitium of the medulla, and less so in the cortex, in all treatment groups. Interstitial edema was evident in all treated groups, particularly in the region of the corticomedullary junction. The glomeruli in all treatment groups showed no obvious changes to the capillary loops or mesangium. There was no increase in cellularity within glomeruli and no glomerulosis (Fig. 2B). Gentamicin on its own showed similar findings to those of indomethacin and ibuprofen (Table 3).

Table 2. Summary of light microscopy and electron microscopy changes in control groups compared to changes seen in groups administered medications antenatally

\begin{tabular}{|c|c|c|c|c|c|}
\hline \multirow[b]{2}{*}{ LM findings } & \multicolumn{5}{|c|}{ Groups } \\
\hline & $\begin{array}{l}\text { Control } \\
n=15\end{array}$ & $\begin{array}{l}\text { Indo } 0.5 \mathrm{mg} \\
\quad n=11\end{array}$ & $\begin{array}{c}\text { Indo } 1 \mathrm{mg} \\
n=7\end{array}$ & $\begin{array}{c}\text { Ibu } 10 \mathrm{mg} \\
n=9\end{array}$ & $\begin{array}{c}\text { Ibu } 20 \mathrm{mg} \\
n=5\end{array}$ \\
\hline $\begin{array}{l}\text { Prox tubular epithelium cytoplasmic } \\
\text { vacuolization and granularity }\end{array}$ & + & + & + & + & + \\
\hline Intraluminal vacuoles & + & + & + & + & + \\
\hline Distal tubule vacuoles & - & - & - & - & - \\
\hline Interstitial lymphocytes & + & + & + & + & + \\
\hline Interstitial edema & - & ++ & ++ & + & + \\
\hline EM findings & $n=7$ & $n=3$ & $n=2$ & $n=4$ & $n=5$ \\
\hline Foot process effacement & $0 \%$ & $70 \%$ & $70 \%$ & $70 \%$ & $80 \%$ \\
\hline $\mathrm{BM}$ protrusions and lucency & - & +++ & +++ & +++ & +++ \\
\hline Mitochondrial changes & - & + & + & + & ++ \\
\hline Microvilli loss & - & + & + & + & ++ \\
\hline
\end{tabular}

$+=$ Mild, $++=$ moderate,$++=$ severe. 


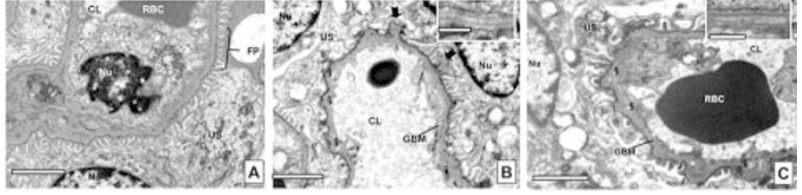

Figure 1. Electron micrograph of glomeruli. (A) Control animal showing normal morphology of the GBM and foot processes. $(B)$ Antenatal treated animal with ibuprofen $20 \mathrm{mg} / \mathrm{kg}$ showing splits, laminations, and "spike"like projections. (C) Antenatal treated animal with indomethacin 0.1 $\mathrm{mg} / \mathrm{kg}$ showing splits, laminations, and "spike"-like projections. CL, capillary lumen; US, urinary space; RBC, red blood cell; $\rightarrow$, "spike"-like projections; §, split; *, lamination; GBM, glomerular basement membrane; FP, area showing the normal appearing foot processes. Scale bars in main images $=2 \mu \mathrm{m}$, Scale bars in inserts $=550 \mathrm{~nm}$.
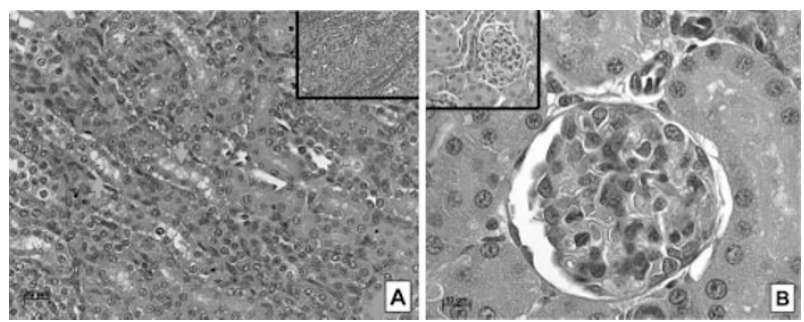

Figure 2. (A) Light microscopy of proximal tubules showing prominent vacuolization and granularity of the cytoplasm of the epithelial cells (arrows) as well as some intraluminal vacuole formation in a postnatal animal treated with ibuprofen $5 \mathrm{mg} / \mathrm{kg}$ and gentamicin $2.5 \mathrm{mg} / \mathrm{kg}$ (inset, control group showing normal proximal tubules). (B) Light microscopy of glomeruli showing no obvious changes to the capillary loops or mesangium in a postnatal animal treated with indomethacin $0.2 \mathrm{mg} / \mathrm{kg}$ (inset, control group).

Electron microscopy. Foot process effacement of 25-80\% was seen in the postnatally treated rat pups, but was not as extensive as in the intrauterine groups except for the combination of indomethacin and gentamicin (Fig. 3, A-C). The splits, laminations, and "spike"-like projections are shown in Figure $4, A-F$. The tubular changes were similar to those of the intrauterine-exposed animals with distal tubules having pleomorphic mitochondria, loss of microvilli and some inflammatory cells (Fig. 5, $A-D$ ) (Table 2). In the samples, it was
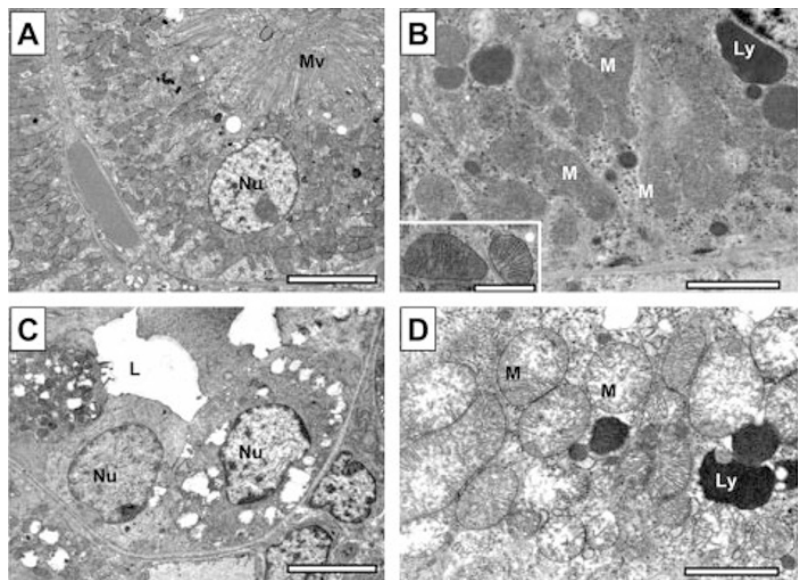

Figure 3. Electron micrograph of distal tubule. (A) Control animal showing a normal tubule. Scale Bar $=5 \mu \mathrm{m}$. (B) Control animal demonstrating the normal appearance of mitochondria in our preparations. Scale Bar $=2 \mu \mathrm{m}$. Inset is a higher magnification of some mitochondria showing the cristae. Scale bars in inserts $=550 \mathrm{~nm}$. (C) Postnatal animal treated with ibuprofen $5 \mathrm{mg} / \mathrm{kg}$ showing the loss of microvilli and mild flattening. Scale Bar $=5 \mu \mathrm{m}$. (D) Postnatal animal treated with indomethacin $0.2 \mathrm{mg} / \mathrm{kg}$ showing mitochondrial swelling with a loss of density to the matrix making the cristae (membrane projections) more visible, these changes were seen frequently in the tubules of the test groups. Scale Bar $=2 \mu \mathrm{m}$. $N u$, nucleus; $M v$, microvilli; $M$, mitochondria; $L$, lumen of tubule; $L y$, lysosome.

possible to see normal appearing mitochondria in tubules adjacent to the tubule containing abnormal appearing mitochondria indicating that this observed change is not processing artefact.

\section{DISCUSSION}

This neonatal rat model demonstrates on EM that substantial glomerular and tubular injury occurs following antenatal administration of indomethacin or ibuprofen, and that this injury has not resolved at the completion of glomerulogenesis. This model also demonstrates that postnatal administration of these medications also results in significant glomerular and tubular injury.

A 5-d postnatal course of indomethacin or ibuprofen in our neonatal rat model covers a more extensive period of glomeru-

Table 3. Summary of light microscopy and electron microscopy changes in control groups compared to changes seen in groups administered medications postnatally

\begin{tabular}{|c|c|c|c|c|c|c|c|c|}
\hline \multirow[b]{2}{*}{ LM findings } & \multicolumn{8}{|c|}{ Groups } \\
\hline & $\begin{array}{l}\text { Control } \\
n=15\end{array}$ & $\begin{array}{l}\text { Indomethacin } \\
\begin{array}{c}0.1 \mathrm{mg} \\
n=7\end{array}\end{array}$ & $\begin{array}{c}\text { Indomethacin } \\
\begin{array}{c}0.2 \mathrm{mg} \\
n=4\end{array}\end{array}$ & $\begin{array}{c}\text { Ibuprofen } \\
5 \mathrm{mg} \\
n=9\end{array}$ & $\begin{array}{c}\text { Ibuprofen } \\
\begin{array}{c}10 \mathrm{mg} \\
n=6\end{array}\end{array}$ & $\begin{array}{c}\text { Gentamicin } \\
2.5 \mathrm{mg} \\
n=11\end{array}$ & $\begin{array}{c}\text { Indomethacin } \\
0.1 \mathrm{mg} \mathrm{\&} \\
\text { gentamicin } \\
2.5 \mathrm{mg} n=5\end{array}$ & $\begin{array}{c}\text { Ibuprofen } \\
5 \mathrm{mg} \mathrm{\&} \\
\text { gentamicin } \\
2.5 \mathrm{mg} n=6\end{array}$ \\
\hline $\begin{array}{l}\text { Prox tubular epithelium cytoplasmic } \\
\text { vacuolization and granularity }\end{array}$ & + & + & ++ & + & + & + & ++ & ++ \\
\hline Intraluminal vacuoles & + & + & ++ & + & ++ & + & ++ focally +++ & ++ focally +++ \\
\hline Distal tubule vacuoles & - & - & + & - & + & + & + & + \\
\hline Interstitial lymphocytes & + & + & + & + & + & + & + & + \\
\hline Interstitial edema & - & ++ & + & ++ & ++ & + & ++ & ++ \\
\hline EM findings & $n=7$ & $n=2$ & $n=3$ & $n=$ & & $n=2$ & $n=2$ & $n=3$ \\
\hline Foot process effacement & $0 \%$ & $25 \%$ & $40 \%$ & $35 \%$ & & $35 \%$ & $40 \%$ & $50 \%$ \\
\hline $\mathrm{BM}$ protrusions and lucency & - & + & ++ & + & & ++ & +++ & +++ \\
\hline Mitochondrial changes & - & + & ++ & + & & + & + & + \\
\hline Microvilli loss & - & - & + & + & & + & + & + \\
\hline
\end{tabular}

$+=$ Mild,$++=$ moderate,$++=$ severe . 


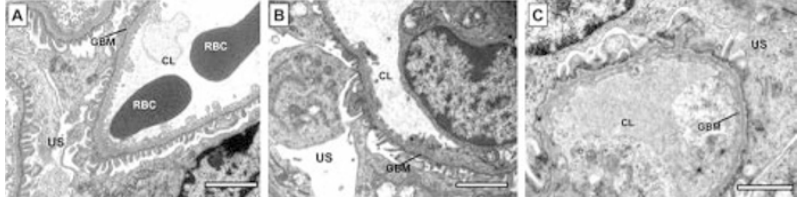

Figure 4. Electron micrograph of glomeruli. (A) Control animal showing no foot process effacement. The foot processes are the tooth-like projections on the urinary space side of the glomerular basement membrane. (B) Postnatal animal treated with ibuprofen $10 \mathrm{mg}$ showing approximately $40 \%$ foot process effacement. (C) Postnatal animal treated with indomethacin 0.1 $\mathrm{mg}$ and gentamicin $2.5 \mathrm{mg}$ showing approximately $80 \%$ foot process effacement. $C L$, capillary lumen; $U S$, urinary space; $R B C$, red blood cell; $G B M$, glomerular basement membrane; $F P$, area showing the normal appearing foot processes. Scale bars $=2 \mu \mathrm{m}$.

logenesis (24-30 wk gestation) in comparison with the human neonate. However, up to $40 \%$ of infants do not have successful closure of the duct and require a second or third course of indomethacin, extending the period they are exposed to these drugs during glomerulogenesis (19-21). Pups in this study were killed at $14 \mathrm{~d}$ of age, and this may not have allowed enough time for the kidney to recover. However, the pups that were exposed to indomethacin or ibuprofen antenatally were noted to have more extensive injury, and had a longer period of recovery before sacrifice. Further studies are required at later time points to determine whether this injury is long-standing, associated with glomerulosclerosis or glomerular loss.

Indomethacin is administered to pregnant women to try and prevent preterm delivery. Adverse effects of indomethacin on the fetus and neonate have been described including oligohydramnios, persistent renal insufficiency, gastrointestinal bleeding and perforation, and persistent pulmonary hypertension (22-26). However, it has not been determined whether there is any effect on fetal glomerular development following exposure to intrauter- ine indomethacin. Our study indicates that glomerular injury occurs with antenatal exposure that has not resolved at term.

The effect of NSAID on the kidney is well documented in the adult. Up to $1 \%$ of the population are thought to experience renal impairment after using NSAID. However, it is often difficult to determine whether the renal compromise is due to the drug or underlying renal disease already present (27). NSAID do not alter the GFR in healthy controls that are euvolemic, however it may be reduced in patients with preexisting chronic renal disease or in the elderly associated with their reduced GFR $(28,29)$. This finding could explain the high rate of acute renal failure (5) following administration of indomethacin in premature neonates who have a very low GFR.

The renal tubular change was evident in all treatment groups. The tubular changes were most evident light microscopically in the groups administrated postnatally with the combination of an NSAID and gentamicin. EM showed more glomerular damage in the groups administered medications antenatally and very little difference in tubular damage between the groups. It is likely that LM is a relatively insensitive way of assessing tubular and glomerular damage unless it is severe. There was not a significant difference in the amount of interstitial edema or lymphocyte infiltrate in either the antenatally or postnatal treatment groups. Pirani et al. (30) reported LM findings of tubular degenerative and regenerative changes coupled to interstitial nephritis in adult renal biopsies with NSAID renal impairment. The infiltrate in these cases were predominantly lymphocytic in nature. The inflammatory infiltrate seen in our neonatal rat model was also lymphocytic. Previous EM studies have demonstrated no glomerular injury or mild effacement of podocyte foot processes (27), which was a prominent feature in our study. There have been a number of case reports of focal glomerulosclerosis, membranous glomer-
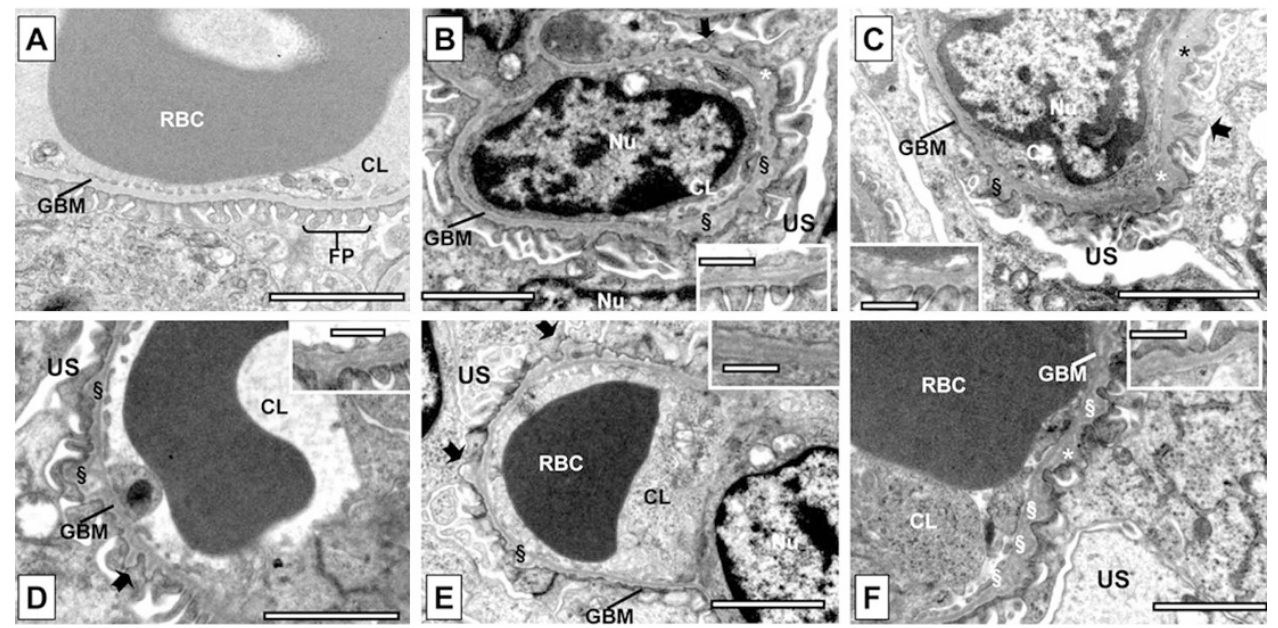

Figure 5. Electron micrograph of glomeruli. (A) Control animal showing normal morphology of the GBM and foot processes. All foot processes in this image are normal. (B) Postnatal animal treated with $2.5 \mathrm{mg}$ gentamicin showing GBM splits, laminations and "spike"-like projections. Inset shows an area of lamination at high magnification. $(C)$ Postnatal animal treated with $0.2 \mathrm{mg}$ indomethacin showing splits, laminations, and "spike"-like projections. Inset shows an area of lamination at high magnification. $(D)$ Postnatal animal treated with $10 \mathrm{mg}$ of ibuprofen showing GBM splits and "spike"-like projections. Inset shows an area of lamination at high magnification. (E) Postnatal animal treated with $0.1 \mathrm{mg}$ indomethacin and gentamicin $2.5 \mathrm{mg}$ showing extensive changes with splits and "spike"-like projections. Inset shows an area of lamination at high magnification. $(F)$ Postnatal animal treated with ibuprofen in $5 \mathrm{mg}$ and gentamicin $2.5 \mathrm{mg}$ showing extensive changes with laminations and splits. "Spike"-like projections were present in areas but are not represented in this micrograph. Inset shows an area of lamination at high magnification. $C L$, capillary lumen; $U S$, urinary space; $R B C$, red blood cell; $\rightarrow$, "spike"-like projections; $\S$, split; *, lamination; GBM, glomerular basement membrane; $F P$, area showing the normal appearing foot processes. Scale bars in main images $=2 \mu \mathrm{m}$, Scale bars in inserts $=550 \mathrm{~nm}$. 
ulonephritis, or proliferative glomerulonephritis associated with NSAID treatment in adult humans. However, because of their rarity it is difficult to determine whether this is causative or incidental (31-34). Gentamicin causes acute tubular necrosis that may also be associated with tubulointerstitial changes seen on LM (35-37). EM changes with gentamicin also only constitute tubular injury $(38,39)$. The differences in the published literature and our results suggest that exposure to these drugs may result in more significant damage during glomerulogenesis that is not evident in the mature glomerulus.

In our study, LM changes principally involved tubular findings with prominent vacuolization and granularity of the cytoplasm of the epithelial cells, as well as some intraluminal vacuole formation. EM findings showed tubular injury with both indomethacin and ibuprofen, predominantly affecting the distal tubules with loss of microvilli, mitochondrial changes, and some inflammatory cells above the tubular basement membrane. Proximal tubules developed vacuoles that contained small amounts of lucent protein a feature rarely seen in the distal tubules of these animals. Gentamicin on its own also produced these changes. Of most significance were the EM changes with marked glomerular involvement with foot process effacement ranging from 25 to $80 \%$. There was also considerable splitting of the basement membrane along with protrusions and lucencies demonstrated. The addition of gentamicin to indomethacin showed the most significant glomerular injury. These changes are quite different and more pronounced in this animal neonatal model than noted in adult animal and human renal biopsy findings.

A reduction in the number of nephrons has been suggested as one of the potential causes for hypertension. A difference in the number of nephrons at birth has been noted in different racial populations (40) along with glomerular size (41), and may be associated with the subsequent increased risk of hypertension in these races. Extremely premature infants frequently have poor extrauterine growth and along with glomerular injury caused by such drugs as indomethacin, ibuprofen, and gentamicin, may result in a reduced number of nephrons and an increased risk of hypertension later in life. There is suggestion from the literature that extremely premature infants are at increased risk of high blood pressure in adulthood (42-45). Evidence of long-term renal impairment has been found by Rodriguez-Soriano et al. (46) with abnormal tubular phosphate transport along with urinary calcium excretion, however, they found no difference in blood pressure. Changes in renal histomorphometry have been noted in extremely premature infants $(47,48)$, indicating that oligonephropathy can occur and may subsequently predispose these infants to renal disease and hypertension later in life. Our study, although not showing glomerulosclerosis, has indicated far more extensive glomerular injury than expected following exposure to these drugs. Further morphometric analysis is required to determine whether this injury has resulted in a decreased number of glomeruli, which may result in later hypertension.

This study of indomethacin, ibuprofen, and gentamicin in a neonatal animal model indicates more extensive glomerular injury than expected from adult animal and human renal biopsies. Exposure to these drugs during glomerulogenesis may have the potential to result in oligonephropathy and subsequent glomerular hyperfiltration and risk for later renal disease. This raises concerns regarding the use of these drugs in extreme premature infants at the time of glomerulogenesis. Unfortunately, at present there are no other medical options to close the ductus arteriosus, but prudent use of indomethacin and ibuprofen, especially in combination with gentamicin should be considered. Further studies are required to determine the long-term renal risk of these drugs in the human preterm neonate.

Acknowledgments. The authors thank Ms. Leigh Vincent in preparation of the tissues for light microscopy and Ms. Natalie de Cure for assistance with animal experimentation.

\section{REFERENCES}

1. Emmanouilides G 1978 Persistent patency of the ductus arteriosus in premature infants: incidence, perinatal factors and natural history. In: Heymann M, Rudolph A (eds). The Ductus Arteriosus; the $75^{\text {th }}$ Conference on Pediatric Research. Columbus, OH, Ross Laboratories, pp 63-69

2. Ellison RC, Peckham GJ, Lang P, Talner NS, Lerer TJ, Lin L, Dooley KJ, Nadas AS 1983 Evaluation of the preterm infant for patent ductus arteriosus. Pediatrics 71:364-372

3. Narayanan M, Cooper B, Weiss H, Clyman RI 2000 Prophylactic indomethacin: factors determining permanent ductus closure. J Pediatr 136:330-337

4. Van Overmeire B, Van deBroek H, VanLaer P, Weyler J, Vanbaesebrouck P 2001 Early versus late indomethacin treatment for patent ductus arteriosus in premature infants with respiratory distress syndrome. J Pediatr 138:205-211

5. Akima S, Kent A, Reynolds GJ, Gallagher M, Falk MC 2004 Indomethacin and renal impairment in neonates. Pediatr Nephrol 19:490-493

6. Pezzati M, Vargi V, Biagotti R, Bertini G, Cianciulli D, Rubatelli FF 1999 Effects of indomethacin and ibuprofen on mesenteric and renal blood flow in preterm infants with patent ductus arteriosus. J Pediatr 135:733-738

7. Akinola O, Norohna C, Oremosu A, Kusemiju O, Okanlawon A 2003 The effect of the cyclooxygenase blockers, ibuprofen on the development of glomeruli in Sprague-Dawley rats. Niger Postgrad Med J 10:46-50

8. Komhoff M, Wang J-L, Cheng H-F, Langenbach R, McKanna JA, Harris RC, Breyer MD 2000 Cyclooygenase-2-selective inhibitors impair glomerulogenesis and renal cortical development. Kidney Int 57:414-422

9. Gilbert T, Gaonach S, Moreau E, Merlet-Benichou C 1994 Defect of nephrogenesis induced by gentamicin in rat metanephric organ culture. Lab Invest 70:656-666

10. Naruse K, Fujieda M, Miyazaki E, Hayashi Y, Toi M, Fukui T, Kuroda N, Hiroi M, Kurashige T, Enzan H 2000 An immunohistochemical study of developing glomeruli in human fetal kidneys. Kidney Int 57:1836-1846

11. Horster MF, Braun GS, Huber SM 1999 Embryonic renal epithelia: induction, nephrogenesis, and cell differentiation. Physiol Rev 79:1157-1191

12. Abrahamson DR 1991 Glomerulogenesis in the developing kidney. Semin Nephrol 11:375-389

13. Lasaitiene D, Chen Y, Guron G, Marcussen N, Tarkowski A, Telemo E, Friberg P 2003 Perturbed medullary tubulogenesis in neonatal rat exposed to renin-angiotensin system inhibition. Nephrol Dial Transplant 18:2534-2541

14. Black MJ, Wang Y, Bertram JF 2002 Nephron endowment and renal filtration surface area in young spontaneously hypertensive rats. Kidney Blood Press Res 25:20-26

15. Skov K, Nyengaard JR, Korsgaard N, Mulvany MK 1994 Number and size of renal glomeruli in spontaneously hypertensive rats. J Hypertens 12:1373-1376

16. Brenner BM, Chertow GM 1994 Congenital oligonephropathy and the etiology of adult hypertension and progressive renal injury. Am J Kidney Dis 23:171-175

17. Keller G, Zimmer G, Mall G, Ritz E, Amann K 2003 Nephron number in patients with primary hypertension. N Engl J Med 348:101-108

18. Zumrutdal AO, Turan C, Cetin F, Adanali S 2002 Relationship between renal size and hypertension in patients with chronic renal failure. Nephron 90:145-147

19. Gersony WM, Peckham GJ, Ellison RC, Miettinen OS, Nadas AS 1983 Effects of indomethacin in premature infants with a patent ductus arteriosus: results of a national collaborative study. J Pediatr 102:895-906

20. Su PH, Chen JY, Su CM, Huang TC, Lee HS 2003 Comparison of ibuprofen and indomethacin therapy for patent ductus arteriosus in preterm infants. Pediatr Int 45:665-670

21. Van Overmeire B, Smets K, Lecoutere D, Van de Broek H, Wegler J, Degroote K, Langhendries JP 2000 A comparison of ibuprofen and indomethacin for closure of patent ductus arteriosus. N Engl J Med 343:674-681

22. Goldenberg RL, Davis RO, Baker RC 1989 Indomethacin induced oligohydramnios. Am J Obstet Gynecol 160:1196-1197

23. Butler-O'Hara M, D'Angio CT 2002 Risk of persistent renal insufficiency in premature infants following the prenatal use of indomethacin for suppression of preterm labour. J Perinatol 22:541-546

24. Vanhaesebrouck P, Thiery M, Leroy JG, Govaert D, de Praeter G, Coppens M, Couvelier C, Dhont M 1988 Oligohydramnios renal insufficiency and ileal perfora- 
tion in preterm infants after intrauterine exposure to indomethacin. J Pediatr 113:738-743

25. Bolisetty S, Patole S, Koh G, Stalewski H, Whitehall J 2001 Neonatal acute haemorrhagic gastritis and antenatal exposure to indomethacin for tocolysis. ANZ J Surg 71:122-123

26. Tarcan A, Gurakan B, Yildrim S, Ozkiraz S, Bilezikci B 2004 Persistent pulmonary hypertension in a premature newborn after 16 hours of antenatal indomethacin exposure. J Perinat Med 32:98-99

27. Whelton A, Hamilton CW 1991 Non-steroidal anti-inflammatory drugs: effects on kidney function. J Clin Pharmacol 31:588-598

28. Ciabattoni G, Cinotti GA, Pierucci A, Simonetti BM, Manzi M, Pugliese F, Barsotti P, Pecci G, Taggi F, Patrono C 1984 Effects of sulindac and ibuprofen in patients with chronic glomerular disease. Evidence for the dependence of renal function on prostacyclin. N Engl J Med 310:279-283

29. Palmer BF, Henrich WL 1995 Clinical acute renal failure with nonsteroidal antiinflammatory drugs. Semin Nephrol 15:214-227

30. Pirani CL, Valeri A, D'Agati V, Appel GB 1987 Renal toxicity of nonsteroidal anti-inflammatory drugs. Contrib Nephrol 55:159-175

31. Artinano M, Etheridge WB, Stroehlein KB, Barcenas CG 1986 Progression of minimal-change glomerulopathy to focal glomerulosclerosis in a patient with fenoprofen nephropathy. Am J Nephrol 6:353-357

32. Kleinknecht D 1993 Diseases of the kidney caused by nonsteroidal antiinflammatory drugs. In: Stewart JH, ed. Analgesic and NSAID-Induced-Kidney Disease. Oxford, UK, Oxford University Press, pp 160

33. Grcevska L, Polenakovic M, Ferluga D, Vizjak A, Stavric G 1993 Membranous nephropathy with severe tubulointerstitial and vascular changes in a patient with psoriatic arthritis treated with non-steroidal anti-inflammatory drugs. Clin Nephrol 39:250-253

34. Radford MG Jr, Holley KE, Grande JP, Larson TS, Wagoner RD, Donadio JV, McCarthy JT 1996 Reversible membranous nephropathy associated with the use of nonsteroidal anti-inflammatory drugs. JAMA 276:466-469

35. Bennet WM, Gilbert DN, Houghton D, Porter GA 1977 Gentamicin nephrotoxicity morphologic and pharmacologic features. West J Med 126:65-68

36. Wilfert JN, Burke JP, Bloomer HA, Smith CB 1971 Renal insufficiency associated with gentamicin therapy. J Infect Dis 124:S148-S155
37. Kourilsky O, Solez K, Morel-Maroger L, Whelton A, Duhoux P, Sraer J 1982 The pathology of acute renal failure due to interstitial nephritis in man with comments on the role of interstitial inflammation and sex in gentamicin nephrotoxicity. Medicine (Baltimore) 61:258-268

38. Houghton DC, Hartnett M, Campbell-Boswell M, Porter G, Bennett W 1976 A light and electron microscopic analysis of gentamicin nephrotoxicity in rats. Am J Pathol 82:589-612

39. Luft FC, Patel V, Yum MN, Patel B, Kleit SA 1975 Experimental aminoglycoside nephrotoxicity. J Lab Clin Med 86:213-220

40. Hughson M, Farris AB 3rd, Douglas-Denton R, Hoy WE, Bertram JF 2003 Glomerular number and size in autopsy kidneys: The relationship to birth weight Kidney Int 63:2113-2122

41. Young RJ, Hoy WE, Kincaid-Smith P, Seymour AE, Bertram JF 2000 Glomerular size and glomerulosclerosis in Australian Aborigines. Am J Kidney Dis 36:481-489

42. Kistner A, Celsi G, Vanpee M, Jacobson SH 2000 Increased blood pressure but normal renal function in adult women born preterm. Pediatr Nephrol 15:215220

43. Kistner A, Celsi G, Vanpee M, Jacobson SH 2005 Increased systolic daily ambulatory blood pressure in adult women born preterm. Pediatr Nephrol 20:232-233

44. Johansson S, Iliadou A, Bergvall N, Tuverno T, Norman M, Cnattingius S 2005 Risk of high blood pressure among young men increases with the degree of immaturity at birth. Circulation 112:3430-3436

45. Irving RJ, Belton NR, Elton RA, Walker BR 2000 Adult cardiovascular risk factors in premature babies. Lancet 355:2135-2136

46. Rodriguez-Soriano J, Aguirre M, Oliveros R, Vallo A 2005 Long-term renal follow-up of extremely low birth weight infants. Pediatr Nephrol 20:579-584

47. Rodriguez MM, Gomez A, Abitbol C, Chandar J, Montane B, Zilleruelo G 2005 Comparative renal histomorphometry: a case study of oligonephropathy of prematurity. Pediatr Nephrol 20:945-949

48. Rodriguez MM, Gomez AH, Abitbol CL, Chandar JJ, Duara S, Zilleruelo GE 2004 Histomorphometric analysis of postnatal glomerulogenesis in extremely preterm infants. Pediatr Dev Pathol 7:17-25 